\title{
Dualband Microstrip Elliptic Patch 1x4 MIMO Antenna Design for 5G System Device
}

\author{
Yusnita Rahayu* \\ Faculty of Engineering \\ Department of Electrical Engineering \\ Universitas Riau \\ Pekanbaru, Indonesia \\ yusnita.rahayu@lecturer.unri.ac.id
}

\author{
Mayo Andika \\ Faculty of Engineering \\ Department of Electrical Engineering \\ Universitas Riau \\ Pekanbaru, Indonesia \\ mayo.andhika1432@student.unri.ac.id
}

*corresponding author: Yusnita Rahayu, yusnita.rahayu@lecturer.unri.ac.id

\begin{abstract}
This paper presents a dual-band antenna for the 5G system communication device. The Multiple Input Multiple Output (MIMO) antenna can potentially boost the capacity and transmission rates to a new level in a communication system. The MIMO 1x4 elliptic patch is designed at $24 \mathrm{GHz}$ and 27.8 GHz. The performance of this antenna is shown in terms of return loss and gain from the simulated $\mathrm{S} 11$ results, a single patch antenna provides $-16.364 \mathrm{~dB}$ at $24 \mathrm{GHz}$ and $-35.44 \mathrm{~dB}$ at 27.86 GHz. While for the MIMO 1x4 patch, the simulated S11 of $-15.563 \mathrm{~dB}$ and $-21.889 \mathrm{~dB}$ are achieved at both $24 \mathrm{GHz}$ and $27.8 \mathrm{GHz}$, respectively. It has a gain value of $9.04 \mathrm{dBi}$ at $24 \mathrm{GHz}$ and a gain value of $6.56 \mathrm{dBi}$ at $27.8 \mathrm{GHz}$. These gains are higher than the gain obtained with a single element. According to the simulation, the proposed antenna achieves the required 5G parameters for the single patch and the MIMO 1x4 patch configuration.
\end{abstract}

Keywords- Elliptic Patch, 5G Antenna, Dual band, MIMO Antenna.

\section{INTRODUCTION}

The growth of telecommunication has drastically forced people to make a new communication system that is faster and better. Converged $5 \mathrm{G}$ networking is emerging as an important research area in next-generation access architectures. An improvement that $5 \mathrm{G}$ brings is the improvement in wireless technology, this includes a cellular system. The purpose of $5 \mathrm{G}$ is to provide the connection to another device through a communication system. $5 \mathrm{G}$ applies many new technologies to improve the information transmission rate. One of the most important technologies is MIMO. The advantages of MIMO technology have included higher spectral efficiency, more signal stability, and greater channel capacity. How to improve the isolation of channels and how to control the reflection loss of antennas are all problems that need to be solved [1].

The issue concerning the MIMO antenna systems is the mutual coupling between the constituent element antennas. Since the 3.5 GHz-band (3400-3600 MHz) and $5 \mathrm{GHz}$-band (4800-5000 MHz) spectra have been identified for 5G mobile communications, developing compact dual-band MIMO antenna systems with high element isolations is of great necessity [2].

The system demands a higher data rate and low latency networks to fulfill the user demands [3]. Critical aspects of 5G research are high bandwidths available to end-user (e.g. $1 \mathrm{~Gb} / \mathrm{s}$ to mobile devices and $10 \mathrm{~Gb} / \mathrm{s}$ to fixed premises, residential or Small and Medium Sizes Enterprises(SMEs)), latency (with a target of $1 \mathrm{~ms}$ delays), lower energy consumption, and higher security [4].

The mm-wave higher frequency ranges from $24.25 \mathrm{GHz}$ to $27.5 \mathrm{GHz}$ have been considered for $5 \mathrm{G}$ cellular networks. Exploring such higher frequencies will allow the usability of large bandwidths and channel capacities. The increase in omnidirectional path loss due to the higher frequencies of mmwave transmissions can be completely compensated through suitable beamforming and directional transmissions [5].

To achieve precise beam steering, considerably more power amplifiers with lower power output (PouT) requirements are needed to be integrated into the frontend modules (FEM) for the massive-MIMO type of $5 \mathrm{G}$ systems to be implemented [6].

For practical application, a microstrip antenna can be completely printed on a common substrate and assembled within a short period. Because of its advantages such as low fabrication cost, high production efficiency, and high manufacturing accuracy, etc., since its invention, the microstrip antenna (printed on the substrate) is widely used today. However, most of the microstrip antennas are planar structures and cannot be applied in three-dimensional (3D) construction [7].

This paper proposes a dual-band 1x4 MIMO antenna with an elliptic patch. The design works at $24 \mathrm{GHz}$ and $27.8 \mathrm{GHz}$. The $24.25 \mathrm{GHz}-29.5 \mathrm{GHz}$ and $37 \mathrm{GHz}-43.5 \mathrm{GHz}$ ranges are the most promising frequencies for the early development of $5 \mathrm{G}$ millimeter-wave systems and it is recommended that at 
least $400 \mathrm{MHz}$ of contiguous spectrum per network be assigned for each frequencies waves [8].

Some company like AT\&T and T-Mobile have also decided to try the $24 \mathrm{GHz}$ bands since the auction that is held are bought highly by both of company and received many positive responses for the possibility of the $24 \mathrm{GHz}$ band. As such, it is also attracting interest for the high-capacity wireless communications, it is useful for 5G's future networking integration [9]. The MIMO $1 \times 4$ antenna elements are composed of four single-elliptic patch antennas. A simple microstrip feeding line feeds the antenna. The proposed antenna shows the simulated gain is higher than $5 \mathrm{dBi}$ as required.

\section{DESIGN OF $24 \mathrm{GHz}$ AND $27.8 \mathrm{GHz}$ DuAl BAND ANTENNA}

\section{A. Single Elliptic Patch Antenna}

Fig. 1 shows the geometry of a single element of the antenna. The substrate is fully grounded with a patch size of 8 $\mathrm{mm} \times 3.5 \mathrm{~mm}$. The design used a single elliptic patch antenna for better bandwidth and gain value for the antenna in $5 \mathrm{G}$ implementation. The single elliptic patch is used to build a MIMO antenna. The antenna used Rogers RO3210 (lossy) as a dielectric substrate having relative permittivity $=10.8$ and a thickness $=0.64 \mathrm{~mm}$. The initial dimension is listed in Table I below.

TABLE I. ANTENNA PARAMETER

\begin{tabular}{|c|c|c|c|}
\hline No & Parameter & Dimension & $\begin{array}{l}\text { Value } \\
(\mathrm{mm})\end{array}$ \\
\hline 1 & $\mathrm{vr}$ & $\begin{array}{l}\text { Elliptic patch } \\
\text { vertical radius }\end{array}$ & 3.5 \\
\hline 2 & ur & $\begin{array}{c}\text { Elliptic patch } \\
\text { horizontal radius }\end{array}$ & 8 \\
\hline 3 & Ws & $\begin{array}{l}\text { Substrate and } \\
\text { ground width }\end{array}$ & 25 \\
\hline 4 & Ls & $\begin{array}{l}\text { Substrate and } \\
\text { ground length }\end{array}$ & 26.8 \\
\hline 5 & st & $\begin{array}{l}\text { Substrate } \\
\text { thickness }\end{array}$ & 0.64 \\
\hline 6 & $\mathrm{pt}$ & $\begin{array}{c}\text { Ground and patch } \\
\text { thickness }\end{array}$ & 0.035 \\
\hline 7 & wf & Feedline width & 0.6 \\
\hline 8 & Lf & Feedline length & 12.5 \\
\hline 9 & $\mathrm{~L} 1$ & Inset feed 1 length & 2.85 \\
\hline 10 & W1 & Inset feed 1 width & 0.5 \\
\hline 11 & L2 & Inset feed 2 length & 2.85 \\
\hline 12 & W2 & Inset feed 2 width & 0.5 \\
\hline 13 & us & $\begin{array}{c}\text { Elliptic slot } \\
\text { horizontal radius }\end{array}$ & 5 \\
\hline 14 & vs & $\begin{array}{c}\text { Elliptic slot } \\
\text { vertical radius }\end{array}$ & 1.2 \\
\hline
\end{tabular}

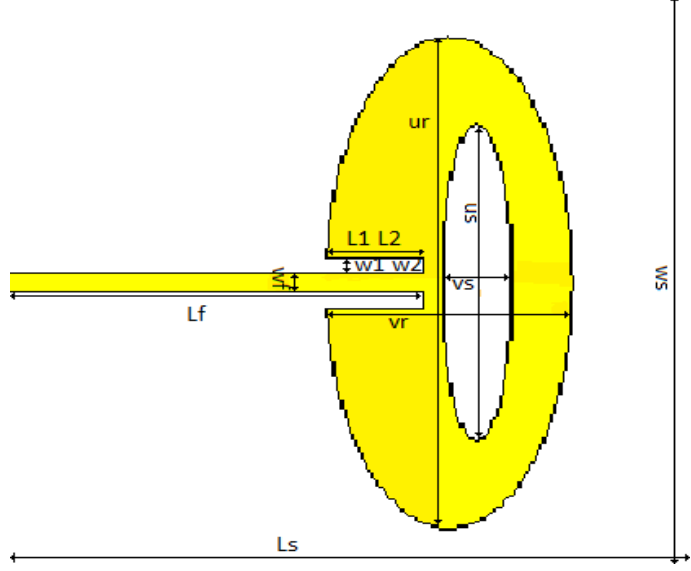

Fig. 1. The geometry of a single elliptic patch antenna.

\section{B. Design of $1 \times 4$ MIMO Elliptic Patch}

The MIMO 1x4 elliptic patch antenna is proposed. The design is composed of four single elliptic patch antennas to meet the expected result as required. They are arranged symmetrically in four pairs of loops. The geometry including critical dimensions of the designed 4-element MIMO antenna system is illustrated in Fig. 2. The distance between each antenna is $10 \mathrm{~mm}$. Four ports were fed by the microstrip feed line. Each elliptic patch size is equal to the previous patch size that it used.

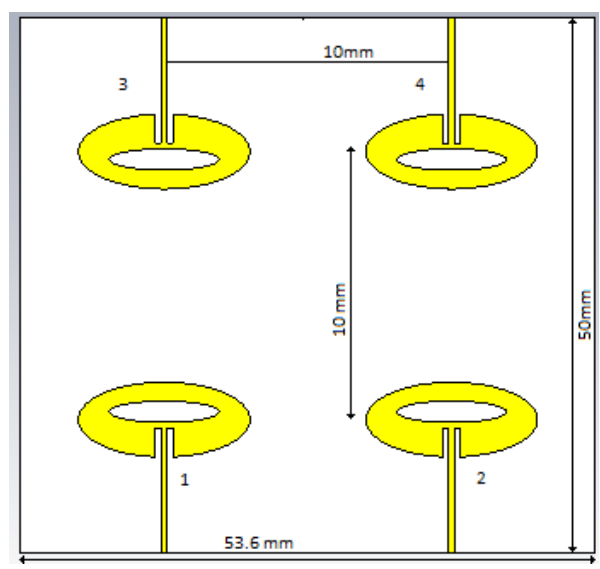

Fig. 2. The geometry of four single elliptic patch antennas.

\section{Simulated Result}

In this section, the S-parameters and radiation patterns are addressed and discussed from the single to the final form of the MIMO antenna design. CST Microwave Studio software is used in this simulation.

\section{A. Single Elliptic Patch}

Optimization has been done to the size of the antenna to obtain the desired frequency. The elliptic slot horizontal radius was optimized from $5 \mathrm{~mm}$ to $5.4 \mathrm{~mm}$. The characterization was performed every $0.5 \mathrm{~mm}$. Fig. 3 shows the simulated S11 results for each of the characterization. It is known that the optimized radius is obtained for $5.4 \mathrm{~mm}$ that close to the desired frequency. 
Fig. 4 shows the simulated S11 of the optimized single element. The simulated S11 are $-16.364 \mathrm{~dB}$ at $24 \mathrm{GHz}$ and $35.44 \mathrm{~dB}$ at $27.8 \mathrm{GHz}$ concerning $-10 \mathrm{~dB}$. The bandwidth obtained is $495 \mathrm{MHz}$ and $334 \mathrm{MHz}$ at $24 \mathrm{GHz}$ and at 27.8 $\mathrm{GHz}$, respectively.

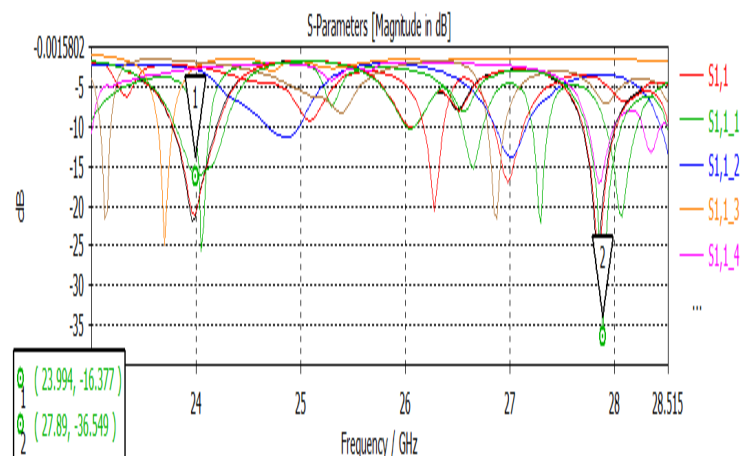

Fig. 3. The simulated S11 characterization on a single elliptic patch.

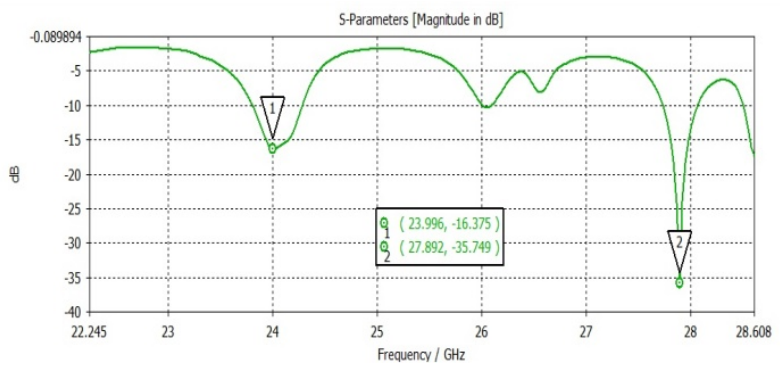

Fig. 4. The simulated S11 of optimized single patch elliptic circular antenna

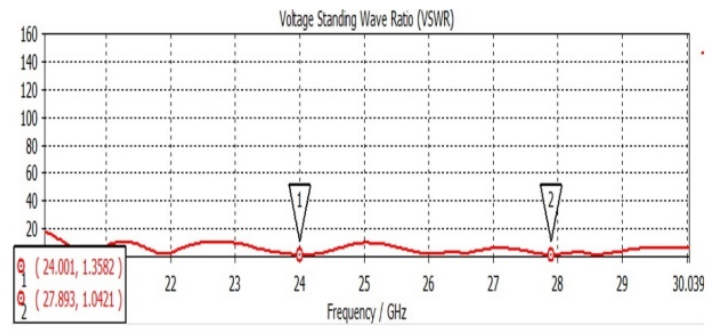

Fig. 5. The simulated VSWR of the optimized single elliptic patch antenna.

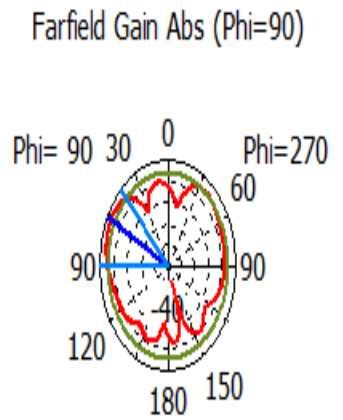

Theta / Degree vs. dBi Side lobe level $=-2.8 \mathrm{~dB}$

Fig. 6. The simulated radiation pattern of the $\mathrm{E}$ and $\mathrm{H}$ plane of the single elliptic patch antenna at $24 \mathrm{GHz}$.

\section{Farfield Gain Abs (Phi=90)}

— farfield $(f=27.5)[1]$

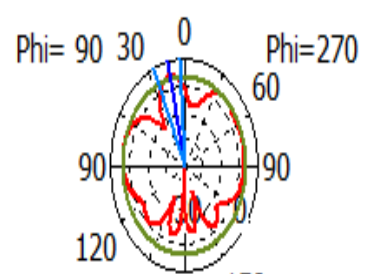

180150
Frequency $=27.5 \mathrm{GHz}$

Main lobe magnitude $=4.36 \mathrm{dBi}$

Main lobe direction $=14.0$ deg.

Angular width $(3 \mathrm{~dB})=20.2 \mathrm{deg}$.

Theta / Degree vs. $\mathrm{dBi} \quad$ Side lobe level $=-1.1 \mathrm{~dB}$
Fig. 7. The simulated radiation pattern of the $\mathrm{E}$ and $\mathrm{H}$ plane of the single elliptic patch antenna at $27.8 \mathrm{GHz}$.

Fig. 5 shows the simulated Voltage Standing Wave Ratio (VSWR) of the optimized single element. The simulated VSWR of the $24 \mathrm{GHz}$ resulted in a value of 1.3582 and of the $27.8 \mathrm{GHz}$ resulted in a value of 1.0421 . The nearly omnidirectional radiation pattern is achieved with the gain antenna of $7.21 \mathrm{dBi}$ for $24 \mathrm{GHz}$ and $4.36 \mathrm{dBi}$ for $27.8 \mathrm{GHz}$ as shown in Fig. 6 and Fig. 7, respectively.

\section{B. 1x4 MiMO Elliptic Patch}

As shown in Fig. 8, the $1 \times 4$ MIMO antenna performs sufficient bandwidth to cover both frequencies, $24 \mathrm{GHz}$ and 27.8 GHz. The simulated S11 of $-15.563 \mathrm{~dB}$ and $-21.889 \mathrm{~dB}$ are achieved at both $24 \mathrm{GHz}$ and $27.8 \mathrm{GHz}$ Also, the isolation between each port is lower than $-30 \mathrm{~dB}$.

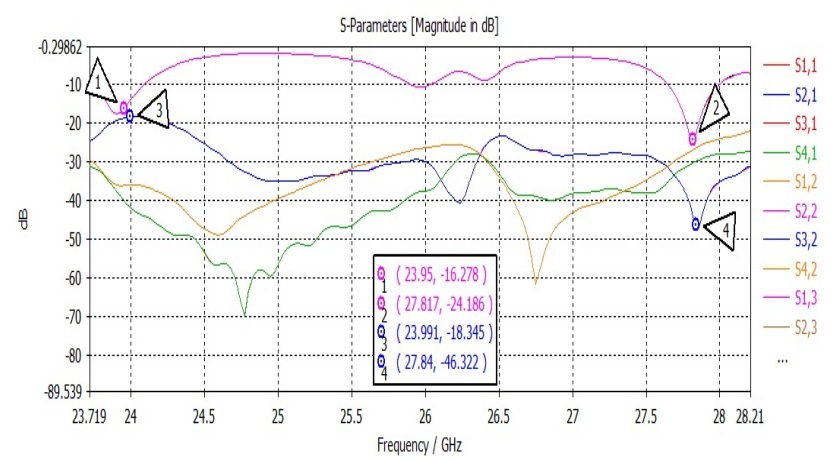

Fig. 8. The simulated S-parameters of the $1 \times 4$ MIMO elliptic patch antenna.

The VSWR at $24 \mathrm{GHz}$ is 1.4385 and at $27.8 \mathrm{GHz}$ is 1.1777 as shown in Fig. 9 with a bandwidth value of $328 \mathrm{MHz}$ and $345 \mathrm{MHz}$. The small bandwidth obtained is due to the MIMO system characteristic used in the antenna design. The radiation pattern of this antenna is nearly omnidirectional which meets the $5 \mathrm{G}$ requirements. The gain value resulted at the $24 \mathrm{GHz}$ is $9.04 \mathrm{dBi}$ with a low sidelobe of $-3.5 \mathrm{~dB}$. For the $27.8 \mathrm{GHz}$, the resulted gain value is $6.56 \mathrm{dBi}$ with a low sidelobe of $-1.4 \mathrm{~dB}$. Both gain values are shown in Fig. 10 and Fig. 11, respectively. It shows that the MIMO system will potentially boost the system to meet the requirement for $5 \mathrm{G}$ 's communication device. 


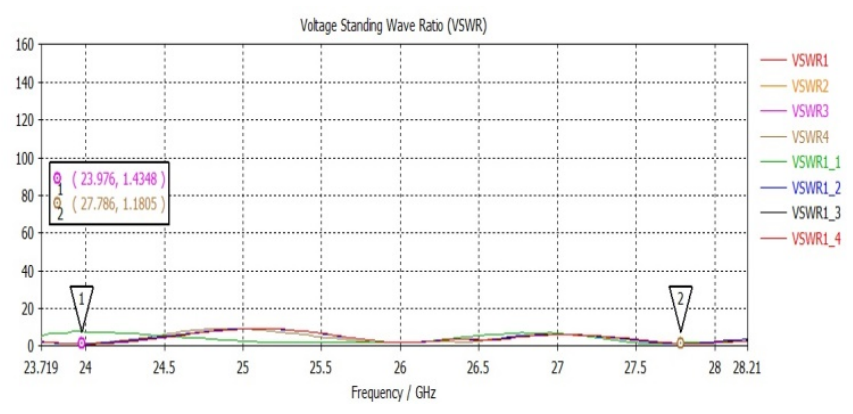

Fig. 9. The simulated VSWR of $1 \times 4$ MIMO elliptic patch antenna.

Farfield Gain Abs (Phi=90)

$$
\text { — farfield }(f=24)[1]
$$

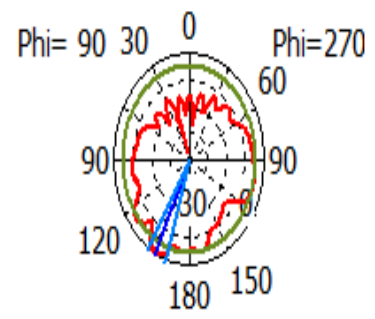

Theta / Degree vs. dBi

Frequency $=24 \mathrm{GHz}$

Main lobe magnitude $=9.04 \mathrm{dE}$ Main lobe direction $=153.0$ deg. Angular width $(3 \mathrm{~dB})=14.4 \mathrm{deg}$

Side lobe level $=-3.5 \mathrm{~dB}$

Fig. 10. The simulated radiation pattern of the $\mathrm{E}$ and $\mathrm{H}$ plane at $24 \mathrm{GHz}$

TABLE II COMPARISON OF THE PROPOSED ANTENNA WITH THE EXISTING PAPER.

\begin{tabular}{|c|c|c|c|}
\hline Reference & $\begin{array}{c}\text { Freq } \\
\text { (GHz) }\end{array}$ & S11 (dB) & $\begin{array}{c}\text { Gain } \\
\text { (dBi) }\end{array}$ \\
\hline This paper & $\begin{array}{c}24 \text { and } \\
27.8\end{array}$ & $\begin{array}{c}-15.563 \\
\text { and } \\
-21.889\end{array}$ & $\begin{array}{c}9.04 \\
\text { and } \\
6.56\end{array}$ \\
\hline$[10]$ & 30 & -33.307 & 6.6 \\
\hline$[11]$ & $\begin{array}{c}3.5 \\
\text { and } 26\end{array}$ & $\begin{array}{c}-21.417 \\
\text { and }- \\
10.819\end{array}$ & $\begin{array}{c}9,176 \\
\text { and } 7.3\end{array}$ \\
\hline$[12]$ & 32.56 & $<-25$ & 6.13 \\
\hline$[13]$ & 60 & -29.899 & 9.66 \\
\hline$[14]$ & 28 and & $<-10$ & 8.4 and \\
& 38 & & 6.1 \\
\hline$[15]$ & 28 and & Both $<-25$ & $\begin{array}{c}12.6 \\
\text { and } 13\end{array}$ \\
\hline & 38 & & \multicolumn{2}{|c}{} \\
\hline
\end{tabular}

Table II lists the comparison between the proposed antenna with the existing references. It shows that our designed antenna has an acceptable performance. It has a higher gain compared to the existing ones with the same frequency range $(24 / 27 \mathrm{GHz})$. MIMO antenna with multi-feed technology is simpler in structure. The dual-band operation is obtained using a simple and well-known technique which is the technique of inserting a slit opening into the radiating element. The proposed antenna system presents a nearly omnidirectional radiation pattern at the two working bands.
Farfield Gain Abs (Phi=90)

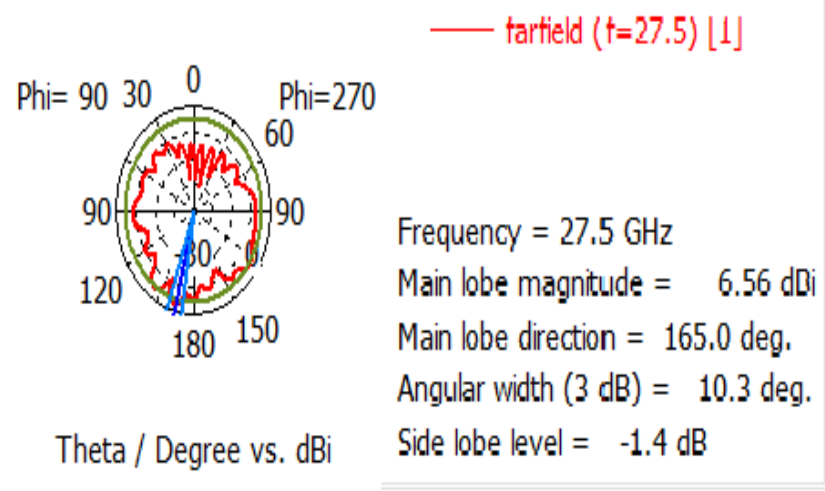

Fig. 11. The simulated radiation pattern of the $\mathrm{E}$ and $\mathrm{H}$ plane at $27.8 \mathrm{GHz}$

\section{CONCLUSION}

In this paper, a new $1 \mathrm{x} 4 \mathrm{MIMO}$ elliptic patch antenna has been designed. The $\mathrm{S} 11$ of $-15.563 \mathrm{~dB}$ and $-21.889 \mathrm{~dB}$ are achieved at both $24 \mathrm{GHz}$ and $27.8 \mathrm{GHz}$. The bandwidth obtained is $331 \mathrm{MHz}$ for $24 \mathrm{GHz}$ and $359 \mathrm{MHz}$ for $27.8 \mathrm{GHz}$. The radiation pattern is nearly omnidirectional with a gain value of $9.04 \mathrm{dBi}$ with a low sidelobe of $-3.5 \mathrm{~dB}$ at the $24 \mathrm{GHz}$ and a gain value of $6.56 \mathrm{dBi}$ with a low sidelobe of $-1.4 \mathrm{~dB}$ at the $27.8 \mathrm{GHz}$. Our proposed antenna uses four patch elements and four ports. The antenna is designed using Rogers $\mathrm{RO} 3210$ (lossy) dielectric substrate having relative permittivity $=10.8$ and a thickness of $0.64 \mathrm{~mm}$. This design meets the requirements for the $5 \mathrm{G}$ communication systems. The $5 \mathrm{G}$ requires the antenna with MIMO capability, and good S11 value $(<-10 \mathrm{~dB})$. Most $5 \mathrm{G}$ antennas have a gain $\geq 5 \mathrm{dBi}$.

\section{REFERENCES}

[1] G. Jing, Y. Liu, X. Zhao, and L. Zhao, "Coupling Reduction of Antenna Array in 5G MIMO Frequency Band below 6GHz Based on Multi-feed Technology," Proc. 2019 IEEE 2nd Int. Conf. Electron. Inf. Commun. Technol. ICEICT, pp. 710-712, 2019.

[2] X. T. Yuan, Z. Chen, J. Li, and T. Yuan, "A Compact Dual-Band and High-Isolation MIMO Antenna System for 5G Smartphone Applications," 2020 IEEE MTT-S Int. Microw. Work. Ser. Adv. Mater. Process. RF THz Appl. IMWS-AMP, Proc., pp. 7-9, 2020.

[3] A. Gaya, M. H. Jamaluddin, I. Ali, and H. Mohamad, "Dual Band Circularly Polarized Rectangular Dielectric Resonator Antenna for millimeter wave 5G Applications," APACE, IEEE Asia-Pacific Conf. Appl. Electromagn. Proc., November, pp. 25-27, 2019.

[4] M. C. Parker, G. Koczian, T. Quinlan, and S. D. Walker, "High capacity communications at $24 \mathrm{GHz}$ and $60 \mathrm{GHz}$ for converged 5G networking”, 20th Eur. Conf. Networks Opt. Commun. NOC, 2015.

[5] A. Dehon, "Fundamental underpinnings of reconfigurable computing architectures," Proc. IEEE, vol. 103, no. 3, pp. 355-378, 2015.

[6] J. Tsay, J. C. Mayeda, J. Lopez, and D. Y. C. Lie, “A Highly Efficient Broadband mm-Wave 24-32.5 GHz SiGe PA for Potential 5G Applications", Midwest Symp. Circuits Syst., vol. August, pp. 714717, 2019.

[7] B. Feng, J. Lai, and C. Y. D. Sim, "A Building Block Assembly Dualband Dual-Polarized Antenna with Dual Wide Beamwidths for $5 \mathrm{G}$ Microcell Applications", IEEE Access, vol. 8, pp. 123359-123368, 2020.

[8] GSMA, "5G Spectrum", Public Policy Position, [Online]. Available: https://www.gsma.com/spectrum/wpcontent/uploads/2016/06/GSMA-5G-Spectrum-PPP.pdf, accessed July, 2016.

[9] Here Are the Big Winners in the FCC's $24 \mathrm{GHz} \& 28 \mathrm{GHz} 5 \mathrm{G}$ Auctions Light Reading." https://www.lightreading.com/mobile/5g/here-are- 
the-big-winners-in-the-fccs-24ghz-and-28ghz-5g-auctions/d/did/751903, accessed Jan. 17, 2021.

[10] B. G. Hakanoglu and M. Turkmen, "An inset fed square microstrip patch antenna to improve the return loss characteristics for 5G applications", 32nd Gen. Assem. Sci. Symp. Int. Union Radio Sci. URSI GASS, August, pp. 1-4, 2017.

[11] L. M. Ramadhan, R. P. Astuti, and B. S. Nugroho, "Simulation of design and analysis massive MIMO array microstrip rectangular patch dualband $3.5 \mathrm{GHz}$ and $26 \mathrm{GHz}$ for $5 \mathrm{G}$ communications", Proc. IEEE Asia Pacific Conf. Wirel. Mobile, APWiMob, pp. 28-32, 2019.

[12] M. Zahid, S. Shoaib, and M. Rizwan, "Wireless Terminals", Int. Conf. Eng. Emerg. Technol., pp. 1-4, 2019.
[13] Y. Rahayu, "New Design of $60 \mathrm{GHz}$ MIMO 2x4 Patch Rectangular Antenna Array for Wireless Gigabit (Wi-Gig) Application", Int. J. Electr. Energy Power Syst. Eng., vol. 2, no. 1, pp. 6-9, 2019.

[14] P. Liu, X. W. Zhu, Y. Zhang, X. Wang, C. Yang, and Z. H. Jiang, "Patch Antenna Loaded with Paired Shorting Pins and H-Shaped Slot for 28/38 GHz Dual-Band MIMO Applications", IEEEAccess, vol. 8, pp. 23705-23712, 2020.

[15] T. Elhabbash and T. Skaik, "Design of dual-band dual-polarized MIMO antenna for mm-wave $5 \mathrm{G}$ base stations with octagonal prism structure", IEEE 7th Palest. Int. Conf. Electr. Comput. Eng. PICECE 2019 . 